\title{
An Econometric Analysis of the US Health Care Expenditure
}

\author{
Amaresh Das \& Frank Martin \\ College of Business \\ Southern University at New Orleans \\ New Orleans, LA 70126, France \\ E-mail: adas2@cox.net, FMartin@suno.edu
}

\begin{abstract}
This paper estimates the determinants of aggregate health care expenditure function for the U.S. by applying a co integration test on a time series data. The evidence presented in the paper supports co integration. The paper lends support to the view that per capita income is the major determinant of aggregate health care expenditure in the U. S. Age of the population, the number of practicing doctors and the share of public finance do not contribute significantly to the explanation of the health care spending. The main policy recommendation that can be drawn from the results is that the health expenditure policy should be coupled not necessarily with the increase in the supply of physicians or policies that promote competition but, with long-run policies that promote human capital. We also find that the mixture of public-private funding does not contribute significantly to the explanation of the health care expenditure in the U.S.
\end{abstract}

Keywords: Unit roots, Co integration, Simultaneity bias

\section{Introduction}

Health spending in the U.S. at about $16.5 \%$ of Gross Domestic Product (GDP) in 2008, will grow to about $19.6 \%$ by 2016 unless drastic reforms take place. Health care spending in America accounts for a larger share of GDP than in any other major industrialized country. The importance of quantitative studies on health care can hardly be over exaggerated. Economists have to date failed to reach an agreement on the main determinants of health care expenditure. Revelli (2002), Mickael and Lauridsen (2009), Joan and Pons-Novell (2007), and others have suggested that it is a reflection of the spatial pattern in local taxation. Suzane and Selden (1998), Theo (1997), Cuyler (1990), Leu (1986) and Hitris and Posnett (1992) have shown the dependence of health expenditure on national income. According to de Haan and Sturm (1994), Pesaram et al (1996), it is dependent on political and institutional factors. Again, Hartwig (2008) has recently argued that it is a reflection of the Baumol's model of unbalanced growth where any wage increase in excess of productivity growth will drive health care expenditure. The purpose of the paper is to assess the relative importance of the factors determining health expenditure function in the U.S. The purpose is not to build any theory underlying the function or to deal with the dynamics of the health care spending dealing data heterogeneity across countries. Our interest is simply to understand why the US health expenditure as a percentage of its GDP is so high.

The paper is an empirical work. There is enough theoretical justification for investigating the health care expenditure. Assuming that the demand for health care is price inelastic, changes in per capita income is theoretically expected to produce a positive effect on the health care spending. Again, if the supply-induced demand for health care hypothesis of health care economics is true, the level of health care expenditure should increase with the increase in the number of physicians. Furthermore, from the public policy perspective public provision increases health care expenditure through two different positive effects on the supply side (1) the effect on the amount of health care provided and (2) the effects on the unit costs at each level of activity. The former arises because bureaucrats in public or non-profit private institutions act like budget maximizers, maximizing their own utility (status, better pay, promotion). The effect on unit costs is expected to be positive owing to the less intensive competition in the public sector, which in turn reduces incentives for cost minimization. Culyer (1989) however, questions this argument and notes that private sector bureaucrats are not necessarily better controlled than their colleagues in the public sector that costs in the private sector many be larger due to advertising and selling costs and that market pressure may be less reliable than professional ethics and regulation.

In addition to GDP per capita, ratio of health care prices to GDP deflator, number of practicing physicians, share of total health care expenditure to public expenditure, our investigation includes other important variables: age structure of the population. Since the financing the internal organization and political restraints of health care 
decision-making are country- specific and heterogeneous (see Federico ( 2002), Costa-Font and Rico (2006), Shun-ichiro and Terai (2008) ), we have undertaken to examine the influence of specific factors on the US aggregate health expenditure. The objectives of the study are:

(i) To model the empirical problem we estimate

(ii) To see if co integration exists between the variables and to see if the dependent (health care expenditure) and independent variables bear an equilibrium relationships to each other.

(iii) To show the effects of aggregate income, institutional and socio-demographic factors on health care expenditure.

\section{Methodology}

Our first step is to find if all the variables entering the health expenditure function are integrated of order one or if they have 'unit roots'. Second, to find if all the variables entering the health expenditure function are linked to the dependent variable in some long-run equilibrium relationship, we need to find if a co integrating vector exists. The co integration test we apply here is due to Granger and Newbold (1974), and Granger and Engle (1984) (Note 1).

Let $\mathrm{y}_{1}, \mathrm{y}_{2} . \quad . \mathrm{y}_{\mathrm{k}}$ be a set of variables, dependent or independent and suppose that each variable is $I$ (1) and therefore, needs differencing to obtain a set of stationary random variables. If $\mathrm{y}_{\mathrm{t}}$ is the $(k, 1)$ vector with $\mathrm{i}^{\text {th }}$ element equal to the value of $y_{i}$ at time $t$, then $y_{t}$ is a vector of $I$ (1) variables. In general any (non-trivial) linear combination of the elements of this vector will be I (1). Thus

$$
\alpha^{\prime} y_{t}=\left[\begin{array}{c}
\alpha_{1} \\
\alpha_{2} \\
\\
\alpha_{k}
\end{array}\right]\left[\begin{array}{l}
y_{1 t} \\
y_{2 t} \\
y_{k t}
\end{array}\right]=\sum_{i=1}^{i=k} \alpha_{i} y_{i t}
$$

If we find a $\alpha$ vector such that $\alpha^{\prime} y_{t}$ is I (0) then any non-trivial scalar multiple of the $\alpha$ vector will also lead to a stationary linear combination of the elements of $y_{t}$. In general, suppose that $\alpha_{i}, i=1,2 \quad r(0<r \leq k-1)$ are linearly independent vectors such that $\left(\alpha_{i}\right)^{\prime} y_{t}$ is stationary. It follows that the $(k, r)$ matrix

$$
\alpha=\left[\alpha_{1}, \alpha_{2} . \alpha_{r}\right]
$$

will have full column rank and that the (r, 1) vector

$$
\alpha^{\prime} y_{t}=\left[\begin{array}{c}
\alpha_{1}^{\prime} y_{t} \\
\alpha_{2 y_{t}}^{\prime} \\
\\
\alpha_{\mathrm{ryt}}^{\prime} y_{t}
\end{array}\right]
$$

will be vector of stationary variables. For now, we shall leave the equation of how we might determine r.

The first task in our methodological design is to determine the order of integration of the variables used. The Augmented Dickey-Fuller (ADF) test is applied for this purpose. We use a reduced - form model and estimate the following equation by using ordinary least squares (Note 2):

$$
\begin{gathered}
\text { PHCE } \left.- \text { PHC }=\beta_{0}+\beta_{1} \text { PCY }+\beta_{2} \text { PHC }- \text { PGDP }\right)+\beta_{3} \text { DOC }+\beta_{4} \text { PF }+\beta_{5} \text { AGE }+\mu \\
\text { PVHC }=\beta_{0}+\beta_{1} \text { PCY }+\beta_{2} \text { RPHC }+\beta_{3} \text { DOC }+\beta_{4} \text { PF }+\beta_{5} \mathrm{AGE}+\mu \\
\mathrm{E}\left(\mu_{i}\right)=0, \operatorname{var}\left(\mu_{i}\right)=\sigma^{2}, \operatorname{cov}\left(\mu_{i}, \mu_{j}\right)=0 \text { for all } i \mp j
\end{gathered}
$$

where

PHCE = the per capita nominal health care expenditure 


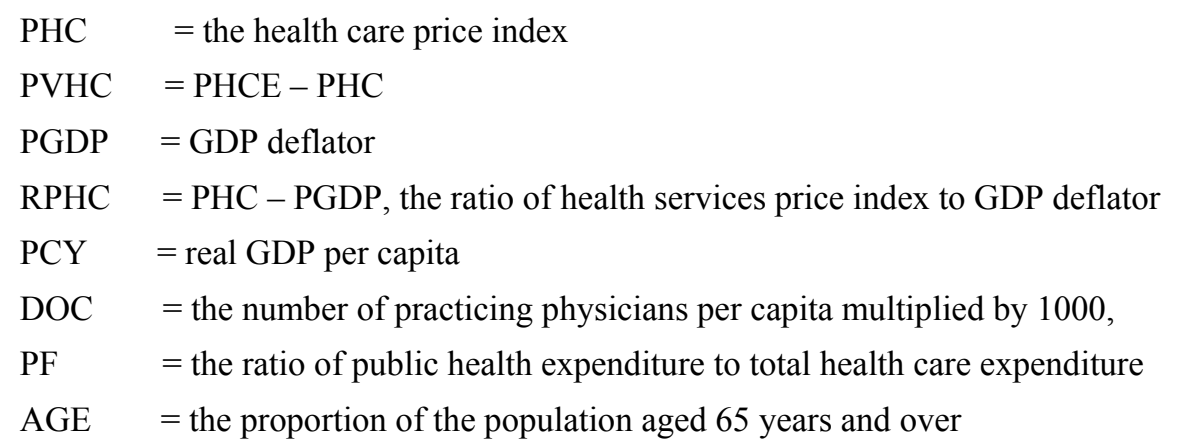

We have used the variables in natural logs so that the regression coefficients directly reflect the elasticity. Variables like fee-for-services, which may dominate in outpatient care, global budgeting and urbanization, may not be important in the U.S. context. Given that all of the series are found to be nonstationary in levels as evidenced by Table 1, the equation (1) is estimated to find if there exists at least one linear combination of these variables which is stationary. To know if the variables are co integrated and to determine the number of co integrating regressions (r), the Johnson's co integration tests are performed and the results obtained are reported. We will do the maximum eigen - value tests and trace tests to ascertain the number of co integrating vectors.

Our study embraces a sample of a homogeneous industrialized market economy which is the U.S and covers a period from 1984 through 2006 using time series (and not cross - sectional as is done in many multi country studies) data. Data are collected from different sources, which are standard data sources for business and economics research: the Financing Health Care Administration, Statistical Abstract of the United States and Plunkett Research - Online Business and Industry Data. Data on the GDP deflator are obtained from IFS (International Financial Statistics, a publication of the International Monetary Fund), CPI, PHC and all other data come from Plunkett Research On-line.

\section{Novelty of the approach}

The actual modeling of our work is essentially based on a general to specific methodology advocated by Hendry and Ericsson (1991). We start from an unrestricted equation from which we progressively derive parsimonious data characterization, guided by the indications given by the data. In moving from the unrestricted to the restricted equation, the classical $\mathrm{F}$ - test is used (the results are not reported here). In addition, misspecification tests of the distributional hypothesis, $\mathrm{y}-\mathrm{x} \beta, \mathrm{N}\left(0, \sigma^{2} \mathrm{I}\right)$, are conducted. The specification of our model (Note 3$)$ of health care expenditure helps remove a potential source of simultaneity bias (Note 4) found in earlier studies, namely, Murthy and Ukpolo (1994), Theo (1997) and others.

The link between this approach and the approaches of the previous studies can be shown simply by adding RPHC (RPHC= PHC - PGDP) to both sides of the general equation (1) that yields (Note 5).

$$
\mathrm{PHCE}-\mathrm{PGDP}=\beta_{0}+\beta_{1} \mathrm{PCY}+\left(\beta_{2}+1\right)(\mathrm{PHC}-\mathrm{PGDP})+\beta_{3} \mathrm{DOC}+\beta_{4} \mathrm{PF}+\beta_{5} \mathrm{AGE}
$$

Since PHCE is described as the natural logarithm of the quantity of health care multiplied by the price of health care, the relative price of health care (that is, PHC - PGDP) is effectively on both sides of equation (1), with the result that the model used in previous studies is more likely to suffer from simultaneity bias. Besides, though less importantly, the coefficients on the relative price variable in earlier models is the price elasticity of demand for health care plus on and not the price elasticity of health care alone. Therefore, we have estimated the equation (1).

\section{Results}

According to the Augmented Dickey Fuller Test (ADF) the variables in equation (1) are all non-stationary in 'levels' (Table 1). The observed t-statistics in the table fail to reject the null hypothesis of the presence of unit root for all the variables in their levels suggesting their non-stationarity Therefore, the equation (1) can only be estimated if there exists at least one linear combination of these variables which is itself stationary, i.e., if the variables are co integrated.

The equation (1) is estimated by the Johansen's Maximum Likelihood procedure (see Johansen and Juselius (1990)) to determine the number of co integrating vectors. The lag structure is determined based on Ljung -Box statistic that suggests the presence of no serial correlation. 
The trace tests in Table 2 rejects the null hypothesis that there is no co integration between the variables, $r=0$, in favor of the alternative that there is one co integrating vector, $r=1$, although the maximum Eigen value test fails to reject it. It is also clear from the trace test that none of the subsequent null hypotheses $[\mathrm{r} \leq 1 \ldots]$ is rejected. The finding of a single co integrating vector means that the variables are linked by some unique long - run equilibrium relationship.

The existence of a long-run equilibrium relationship among the dependent and the independent variables implies that the residuals from the co integrating regression can be used by an error correction term $\mathrm{EC}_{\mathrm{t}-1}$, to explain the system's short-run dynamics. The estimate of the error correction model (ECM) model with the accompanying t-statistics is reported in Table 4.

Table 3 shows the normalized coefficients solely by normalizing variance inflated by a potential multi collinearity problem. The coefficient of the variable PCY as presented in Table 3 is statistically significant and is consistent with those in Table 4. The sign is also consistent with the recent findings, although the signs of the coefficients of the other variables like RPHC, AGE, DOC and PF are not. In the US, as is also found in Jorge et al (2009) and a few other studies though dealing with a cross-section of countries, a low price elasticity of demand may refer to health care being a 'necessity'. The most important finding of our result is that that per capita income becomes a single major determinant of aggregate health expenditure in the U.S. The income elasticity of per capita health expenditure according to chi-square test applied is significantly different from one. The magnitude of the coefficient on PF indicates that a larger share of public financing does not seem to be characterized by higher health care expenditure (Note 6).

The estimate of the error-correction model is given in Table 4. The significance of the coefficient of the error-correction term, $\mathrm{EC}_{\mathrm{t}-1}$ suggests an existence of a long-run equilibrium relationship among the dependent and independent variables in equation (1). The residuals from the co integrating regression used as the error-correction term explain the system's short-run dynamics (Engle and Granger (1974)). The LM, RESET and NORM as reported in Table 4 confirms the absence of serial correlation and non-normality (see Maddala and Kim In-Moo (1998). A word of caution: the absence of variables we eliminated by the Box- Cox transformation, if correlated with other independent variables included, say, physician's supply, DOC, may impair the results. The errors in the measurement of the variables, too, may bias the results (Note 7).

\section{Policy implications}

Based on our findings an important policy implication follows: the coefficient on DOC being not significant in our result, policies designed to increase the supply of doctors may not lead to lowering of the growth of health care expenditure. Our findings also suggest that the public financing of aggregate health expenditure does not carry any relevance in the context of U.S. aggregate health spending. The coefficient on PF, although it is positive, is found to be statistically not significant. It is to be noted that the U.S. open-ended system with the multiple finance sources may ultimately provide no incentive to contain expenditure. We find that the age structure does not seem to be related to the aggregate per capita health spending. However, whatever may be the outcome, age being not so much within the control of health care authority, the policy makers should concentrate more on investment in human capital to enhance health care education with consequential benefits. This result seems to be consistent with the American Hospital Association's findings that show a dramatic fall in the entry of hospitals as well as in the lengths of stay in the hospitals during the past several years. The substantial reduction in admission to hospitals for those under - 65 would demand an alternative explanation (Note 8). The length of stay reduction that has occurred especially with the over-65s may be explained by financial incentives coming through changes in the Medicare Act, TEFRA and the DRG system.

\section{Conclusion}

We provided a quantitative explanation of the determinants of aggregate health care expenditure using a co integration procedure. The evidence in the paper supports co integration. The results also indicate that per capita income contributes significantly to the explanation of the health care expenditure. Age of the population, the number of practicing doctors and the ratio of public health expenditure to total health care expenditure do not seem to have any big impact on aggregate health care expenditure in the U.S.

We did not probe into the financing mechanism; in particular, the degree of the open-endedness of financing that may be characterized by multiple finance sources (insurance companies) or fee-for-service factors. We ignored the financing mechanism and the degree of open-endedness believing that it will be more relevant in the distribution per se of financing and the provision between public and private institutions. Furthermore, for future research, in addition to the advantage of an increase in the sample size, an international comparison may be needed to allow for the inclusion of other aspects of relationships, namely, the temporal stability of the health 
expenditure function. A potential does also exist to examine expenditure spillovers across the geography of the country and the influence of political ideology of parties involved in health care decision-making.

\section{References}

De Haan, Jakob and Sturm, Jan-Egbert. (1994). Political and institutional determinants of fiscal policy in the European Community. Public Choice, 80, pp 157-172

Shun-ichiro, Bessho and Kiniko, Terai. (2008). Competition for private capital and central grants: the case of Japanese industrial parks. Working Paper, 080909, University of California-Irvine, Department of Economics.

Culyer, A. J. (1990). Cost containment in Europe in health care system in transition, OECD, Paris, 29-40.

Hitris, T and Posnett, J. (1992). The determination and effects of health expenditure in developed countries, Journal of Health Economics, 11, pp 173-181.

Granger, C.W.J and Newbold, P. (1974). Spurious regressions in econometrics. Journal of Econometrics, 2, pp 111-120.

Granger, C.W.J and Engle, R. F. (1984). Application of spectral analysis in econometrics in D. R. Brillinger and P. R. Kishnaiah (eds) Handbook of Statistics, 5, Amsterdam, Elsevier.

Hartwig Jochen. (2008). What drives health care expenditure? Baumol's model of unbalanced growth revisited. Journal of Health Economics, Elsevier, 2, pp 603-523.

Hendry, D,F, and J. F. Ericsson. (1991). An econometric analysis of U.K. money demand in monetary trends in the United States and the United Kingdom by Milton Friedman and Anna J. Schwarz. American Economic Review, 81, pp 8-38.

Joan,Costa-Font and Jordi Pons- Novell. (2007). Public health expenditure and spatial interactions in a decentralized national health system. Health Economics. John Wiley, 16, pp 291-306

Joan Costa -Font and Ana Rico. (2006). Devolution and the interregional inequalities in health and healthcare in Spain. Regional Studies, 40, pp 875-887.

Johansen, S. (1998). Statistical analysis of co integration vectors. Journal of Economic Dynamics and Control, 12 , pp 231-254.

Johansen, S and Jusselius, K. (1990). Maximum likelihood estimation and inference in co integration with application to the demand for money. Oxford Bulletin of Economics and Statistics, 52, pp 169-210.

Jorge Alcalde-Unzu, Roberto Ezcurra and Pedro Pascal. (2009). Cross-country disparities in health care expenditure: a factor decomposition. Health Economics, John Wiley \& Sons, 18, pp 479-485.

King, Alan and Hansen Paul. (1996). Aggregate health care expenditure in the United States: evidence from co integration tests. Economics Letters, 3, pp 37-39.

Leu, R. R. (1986). The Public-private mix and international health care cost in public and private health services: complementaries and conflicts (eds) A.J. Culyer and B.Johnson, Basil Blackwell, Oxford.

Maddala, G. S. and Kim, In-Moo. (1998). Unit roots, co integration and structural change, Cambridge University Press, Cambridge.

McCoskey, Suzane and Selden, Thomas, M. (1998). Health care expenditure and GDP: panel data unit root test results. Journal of Health Care Economics, Elsevier, 17, pp 369-376.

Murthy, N.R.V. and Ukpolo, V. (1994). Aggregate health care expenditure in the Unites States: evidence from co integration tests. Applied Economics, 26, pp 797-802.

Mickael Bech and Jorgen Lauridsen. (2009). Exploring spatial patterns in general practice expenditure. The European Journal of Health Economics, 10, pp 243-254

Muscatelli, V, A. and Hurn, S. (1992). Cointegration and dynamic time series models. Journal of Economic Surveys, 6, pp 1-43.

Pesaram, M. H, Shin, Y and Smith, R.J. (2006). Testing for the existence of a long-run relationship, Cambridge working papers in economics 9622, Faculty of Economics, University of Cambridge.

Revelli, Federico. (2002). Testing the tax momicking versus expenditure spill- over hypothesis using English data. Applied Economics, 34, pp1723 - 1731. 
Phillips, P.C.B. and Peron, P. (1988). Testing for a unit root in time series regression. Biometrica, 75, pp 335-346.

Shun-ichiro, Bessho and Kiniko, Terai. (2008). Competion for private capital and central grants: the case of Japanese industrial parks. Working Paper, 080909, University of California- Irvine, Department of Economics.

Smith, Vernon L. (1982). Microeconomic systems as an experimental economics. American Economic Review, 72, pp 923-955.

Theo, Hitiris. (1997). Health care expenditure and integration in the countries of the European Union. Applied Economics Letters, Elsevier, 3, pp 357-361.

Peron, P. (1998). Trends and random walks in macroeconomic time series: further evidence from a new approach. Journal of Economic Dynamics and Control, 12, pp 297-332.

Zellner, A. (1962). An efficient method of estimating seemingly unrelated regression and tests for regression on bias. Journal of the American Statistical Association, 57, pp 348-368.

\section{Notes}

Note 1 . In the real world it is unlikely that a health care system will ever be in precise equilibrium since shocks and unexpected changes to it will always occur. However, departures from equilibrium should not be too large and there should always be a tendency to return to equilibrium after a shock occurs. Hence, if an health expenditure model that implies an equilibrium relationship exits between health expenditure and the variables affecting it, then we should observe these two as being co integrated. For an excellent survey on co integration test, see Muscatelli and Hurn (1992)

Note 2. If, say, $\mathrm{Y}$ is the variable and we write

$$
\begin{gathered}
\Delta \mathrm{y}_{\mathrm{t}}=\beta_{1}+\beta_{2} \mathrm{t}+\delta \mathrm{y}_{\mathrm{t}-1}+\alpha_{\mathrm{i}} \sum_{\mathrm{i}=1}^{\mathrm{m}} \Delta \mathrm{y}_{\mathrm{t}-\mathrm{i}}+\varepsilon_{\mathrm{t}} \\
\Delta \mathrm{y}_{\mathrm{t}-1}=\left(\mathrm{y}_{\mathrm{t}-1}-\mathrm{y}_{\mathrm{t}-2}\right), \Delta \mathrm{y}_{\mathrm{t}-2}=\left(\mathrm{y}_{\mathrm{t}-2}-\mathrm{y}_{\mathrm{t}-3}\right) \text {, etc }
\end{gathered}
$$

where $\varepsilon_{t}$ is a pure noise error term and where the number of lagged difference terms to include is often determined empirically, the idea being to incorporate enough terms so that the error term in (1) is serially uncorrelated. In the ADF test, we will determine if $\delta=0$. The ADF test follows the same asymmetric distribution as the DF statistic, so that the same critical values can be used. The ADF test adjusts the error terms by adding the lagged difference terms of the regressand, although Phillips and Peron (1988) use nonparametric statistical methods without adding lagged difference terms. Since the asymmetric distribution of the Phillips and Peron test is the same as the ADF test statistic, we can as well use Phillips and Peron's test.

Note 3. $\mathrm{PHCE}=\beta_{1} \mathrm{PCY}^{\beta_{2}}(\mathrm{PCH}-\mathrm{PGDP})^{\beta_{3}} \mathrm{DOC}^{\beta}{ }_{\mathrm{PF}^{\beta}} \mathrm{AGE}^{\beta} 6$

We assume that the consumption of health care is unevenly distributed over the life cycle.

The Box- Cox power transformation was conducted to analyze the functional form of the bivariate relationship between health care expenditure per capita and GDP. The results indicated that double log form is preferable to other functional form. The reason for our single choice of GDP per capita in the Box-Cox model is that the variable statistically has been shown to be the most important factor. The linear, exponential and semi-log linear form is all rejected in hypothesis testing, see appendix.

Note 4. Compare single equation : $y=\beta_{0}+\beta_{1} x_{1}+\varepsilon$ to a simple two-equation simultaneous

system: $\mathrm{y}_{1}=\phi_{0}+\phi_{1} \mathrm{y}_{2}+\varepsilon_{1}$ and $\mathrm{y}_{2}=\gamma_{0}+\gamma_{1} \mathrm{y}_{1}+\varepsilon_{2}$ The simultaneity bias occurs if $\mathrm{y}_{1}$ is correlated with $\varepsilon_{2}$. For a good review see Zellner (1962)

Note 5. See King and Hansen (1996).

Note 6. May be, PF is a measure that simply reflects technical production considerations rather than the relative efficiency between public and private institutions. A proxy that measures the share of inpatient expenditure to total health care expenditure (inpatient/total) might not be any more satisfactory

Note 7. A new approach to modeling demand offers an important addition to the conceptual literature. This is through, what is known as, 'induced demand'. Inducement may be most common for surgery, and least common in 'primary care' specialists, because of the repeat-visit nature demand in the latter case., which provides a clear opportunity to measure opportunity to measure 'aggressiveness' of doctors, as well as the obvious joint production of information and treatment. 
Note 8. One possible explanation is a significant shift into cost conscious 'health plans' such as PPOs. IPAs and HMOs and the like. Yet one must wonder if a heightened willingness of physicians to participate in such plans is the ultimate consequence of higher physician supplies. The main effect may occur through the increased willingness of physicians to participate in contractual agreements that provide strong incentives to reduce rates of medical treatment

Table 1. Test for Unit Root

\begin{tabular}{lll}
\hline Variables & ADF & $\begin{array}{c}\text { First Difference } \\
\text { Level }\end{array}$ \\
\hline In PVHC & $-2.222(3)$ & $-6.667(1)$ \\
In PCY & $-2.441(3)$ & $---4.213(1)$ \\
In RPHC & $-1,231(3)$ & $-5.010(2)$ \\
In DOC & $-2.333(3)$ & $-4.765(1)$ \\
In PF & $-2.111(3)$ & $-4.330(1)$ \\
In AGE & $-2.323(3)$ & $-4.231(2)$
\end{tabular}

The critical values at the 5\% level are -3.65 (ADF).

Lags $\backslash$ are in parentheses.

Table 2. Test for co integrating vectors

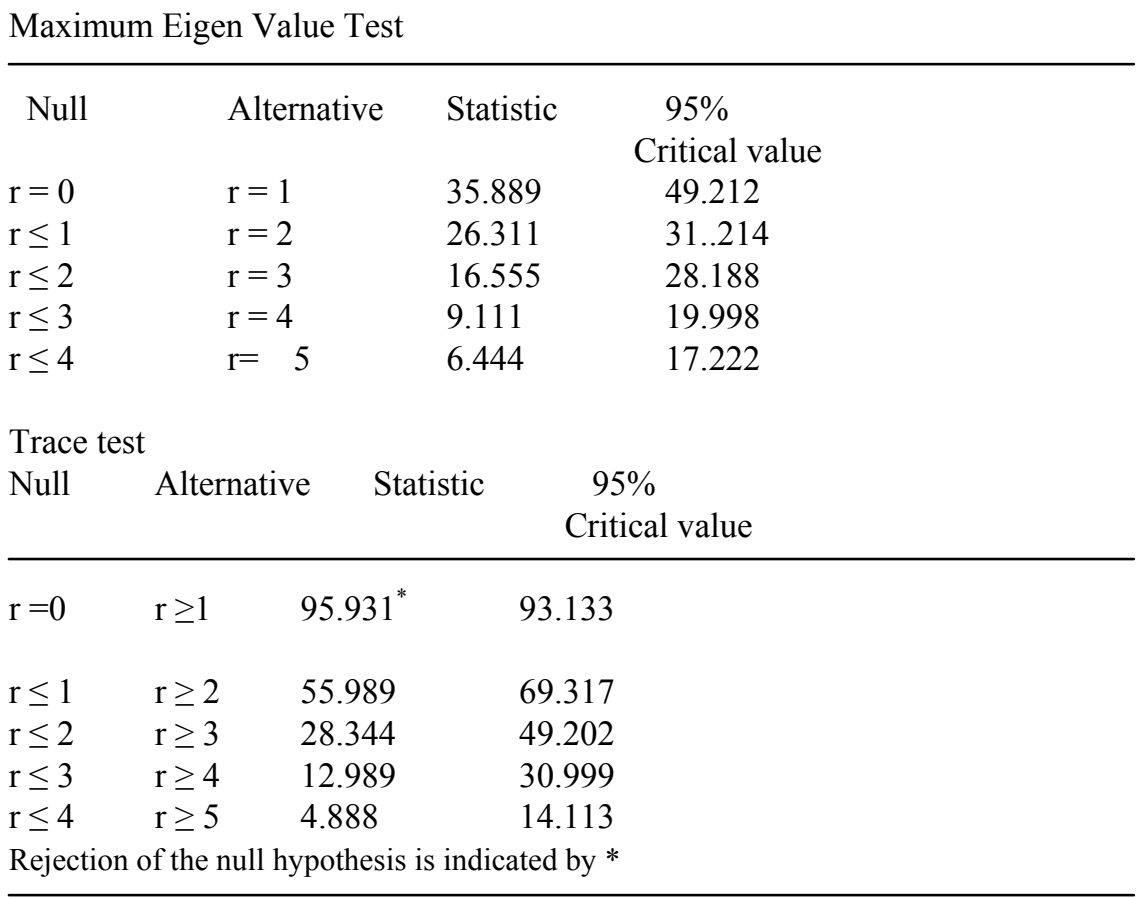


Table 3. Johansen co integration results

\begin{tabular}{|c|c|c|c|c|c|}
\hline \multirow[b]{2}{*}{ In PVHC } & \multicolumn{4}{|c|}{ Normalized Coefficients } & \multirow[b]{2}{*}{ In $\mathrm{AGE}$} \\
\hline & In $\mathrm{PCY}$ & In RPHC & In DOC & In $\mathrm{PF}$ & \\
\hline$-1.000^{\mathrm{a}}$ & $2.681^{\mathrm{b}}$ & $0.450^{\mathrm{a}}$ & $0.555^{\mathrm{a}}$ & $0.231^{\mathrm{a}}$ & $1.239^{\mathrm{a}}$ \\
\hline \multicolumn{6}{|c|}{${ }^{a}$ Not significant at $5 \%$} \\
\hline \multicolumn{6}{|c|}{ bignificant at $5 \%$; tests have $\psi^{2}$ distribution under the null hypothesis. } \\
\hline
\end{tabular}

Table 4. The error correction model

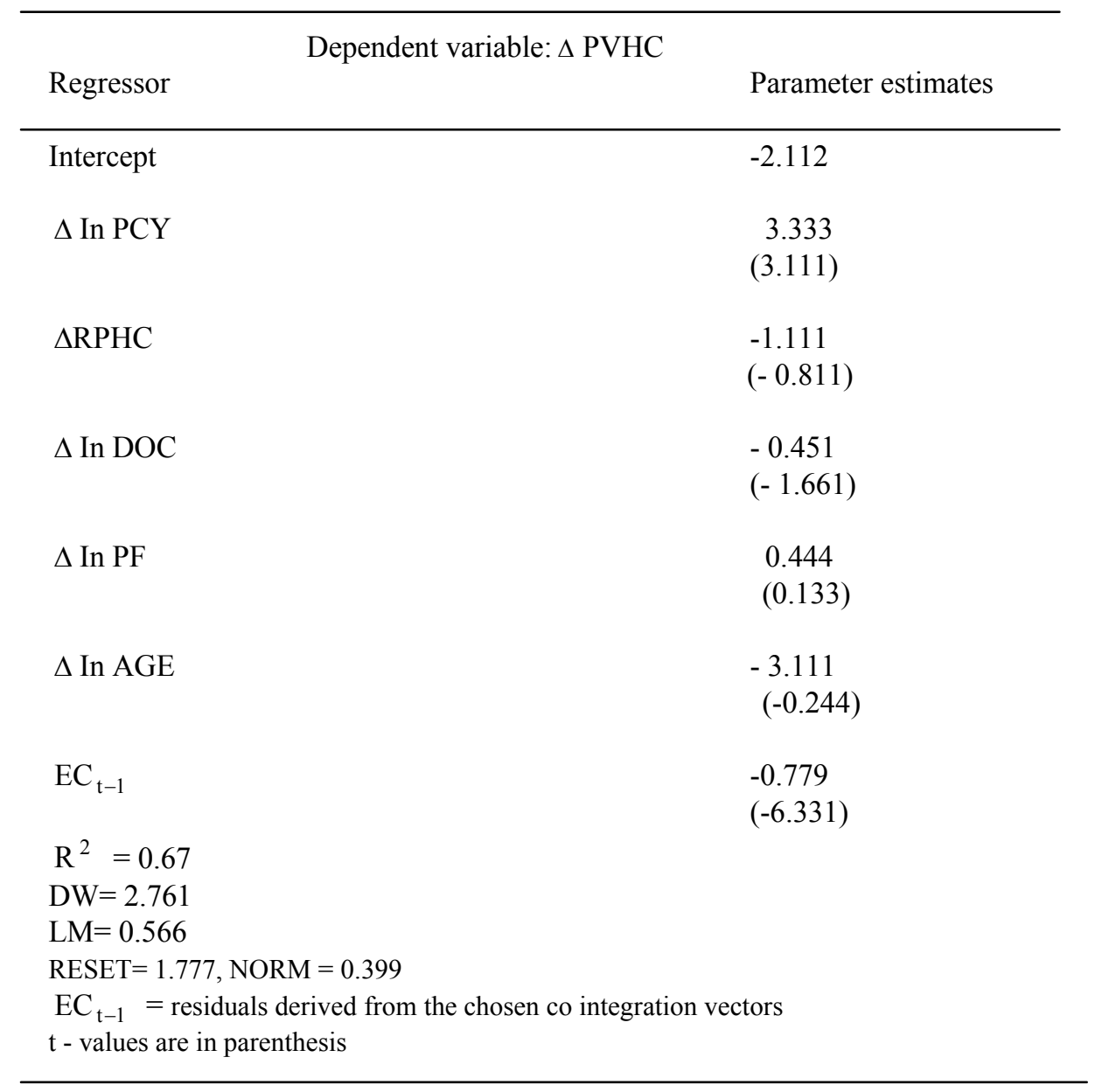




\section{Appendix 1.}

This appendix analyses the issue of the functional form within the Box-Cox transformation. Unlike the standard regression model, the Box-Cox model assigns two parameters to each regressor in the following way:

$$
y \frac{L y}{i}=\beta_{1}+\beta_{2} X \frac{L x}{i}+s_{i}
$$

Where $\mathrm{L}\left(\mathrm{L}_{\mathrm{y}} ; \mathrm{L}_{\mathrm{x}}\right)$ are so-called Box-Cox transformation parameters and $\varsigma_{\mathrm{i}}$ are $\mathrm{N}$ independent random disturbances terms which are assumed to be normally distributed with the zero mean and constant variance, $\sigma^{2}$. The transformations are carried out as $(Z=y, X)$ :

$$
\begin{gathered}
\mathrm{Z}^{\mathrm{L}}=\left(\mathrm{Z}^{\mathrm{L}}-1\right) / \mathrm{L} \quad \text { for } \quad \mathrm{L} \neq 0 \text { and } \\
\mathrm{Z}^{\mathrm{L}}=\mathrm{In} \mathrm{Z} \quad \text { for } \mathrm{L}=0
\end{gathered}
$$

The unknown parameters $L\left(L_{y} ; L_{x}\right)$ determine the functional form within the Box-Cox power family, whereas the unknown parameters $\left(\beta_{1}, \beta_{2}\right)$ determine the intercept and the coefficients of the transformed model. For example, the restriction $\mathrm{L}\left(\mathrm{L}_{\mathrm{y}} ; \mathrm{L}_{\mathrm{x}}\right)=(1,1)$ implies that $(1)$ becomes linear.

$$
y_{i}=\left(\beta_{1}-\beta_{2}+1\right)+\beta_{2} X_{i}+\varsigma_{i}
$$

Since this method is very complicated technically with a model including a large number of regressors, the Box-Cox transformation analysis is restricted to the bivariate regression of GDP per capita on health care expenditure. The reason for our choice of GDP per capita in the bivariate Box-Cox method is the variable statistically has been shown to be the most important factor.

A 2-dimensional grid search procedure is used to approximate maximum likelihood estimates of $L\left(L_{y} ; L_{x}\right)$. The range of the grid search is -1 to 1 , and the grid steps are 0.25 . The results are shown in Table appendix.

The pairs of transformation parameters maximizing the generalized likelihood function are ML $(0 ;-0.25)$ 
Appendix Table 1. Dimensional grid search for Lambda $-\mathrm{Y}\left(\mathrm{L}_{\mathrm{y}}\right)$ and

$$
\text { Lambda }- \text { Z ( Lz). Log ( L; Ly, Lz) } \text { RPHC }^{\text {Ly }}
$$

$$
\beta_{1}+\beta_{2} \mathrm{GDP}^{\mathrm{Lz}}
$$

\begin{tabular}{llllllllll}
\hline & & & \multicolumn{7}{c}{$\mathrm{L}_{\mathrm{y}}$} \\
\cline { 5 - 9 } $\mathrm{L}_{\mathrm{x}}$ & -1.00 & -0.75 & 0.50 & -0.25 & 0.00 & 0.25 & 0.50 & 0.75 & 1.00 \\
-1.00 & -143.8 & -120.6 & -114.3 & -112.2 & -116.2 & -120.4 & -122.4 & -126.0 & -131.1 \\
-0.75 & -145.7 & -122.3 & -116.2 & -114.2 & -115.2 & -118.1 & -120.5 & -123.2 & -128.7 \\
-0.50 & -147.2 & -123.8 & -118.0 & -117.3 & -118.1 & -120.0 & -123.2 & -124.2 & -130.0 \\
-0.25 & -149.8 & -125.2 & -120.3 & -119.4 & -121.4 & -122.3 & -125.3 & -126.3 & -132.1 \\
0.00 & -151.9 & -128.4 & -122.4 & -121.8 & -123.0 & -123.9 & -127.8 & -128.5 & -134.4 \\
0.25 & -152.2 & -130.1 & -124.1 & -123.1 & -125.0 & -124.2 & -129.4 & -129.8 & -135.8 \\
0.50 & -153.2 & -132.2 & -126.2 & -124.5 & -127.1 & -126.2 & -131.1 & -130.3 & -137.1 \\
0.75 & -155.0 & -134.5 & -128.3 & -126.2 & -129.2 & -128.0 & -133.1 & -132.0 & -139.0 \\
1.00 & -157.0 & -135.2 & -130.0 & -128.1 & -131.1 & -130.0 & -135.2 & -134.2 & -141.5 \\
& & & & & & & &
\end{tabular}

Having approximated the generalized maximum likelihood values we can proceed to test the hypothesis about particular $\left(\mathrm{L}_{\mathrm{y}} ; \mathrm{L}_{\mathrm{x}}\right)$ values. The difference between the maximum likelihood value and the likelihood value conditional on the lambda pairs under the null hypothesis multiplied by 2 is approximately $\lambda^{2}$ distributed with two degrees of freedom. Four null hypotheses are tested against the pairs of transformation parameters that maximized the likelihood function $\left[\mathrm{L}_{\mathrm{y}} ; \mathrm{L}_{\mathrm{x}}=(0 ;-0.25)\right]$ : the double $\log$ form $\mathrm{L}_{\mathrm{y}} ; \mathrm{L}_{\mathrm{x}}=(0 ; 0)$, the linear form $\mathrm{L}_{\mathrm{y}} ; \mathrm{L}_{\mathrm{x}}=(1 ; 1)$, the exponential form $\mathrm{L}_{\mathrm{y}} ; \mathrm{L}_{\mathrm{x}}=(1 ; 0)$. The results are shown in table 2 . Given the results here, the unrestricted form model is estimated.

Appendix Table 2. Constraints tested using the Likelihood Ratio test

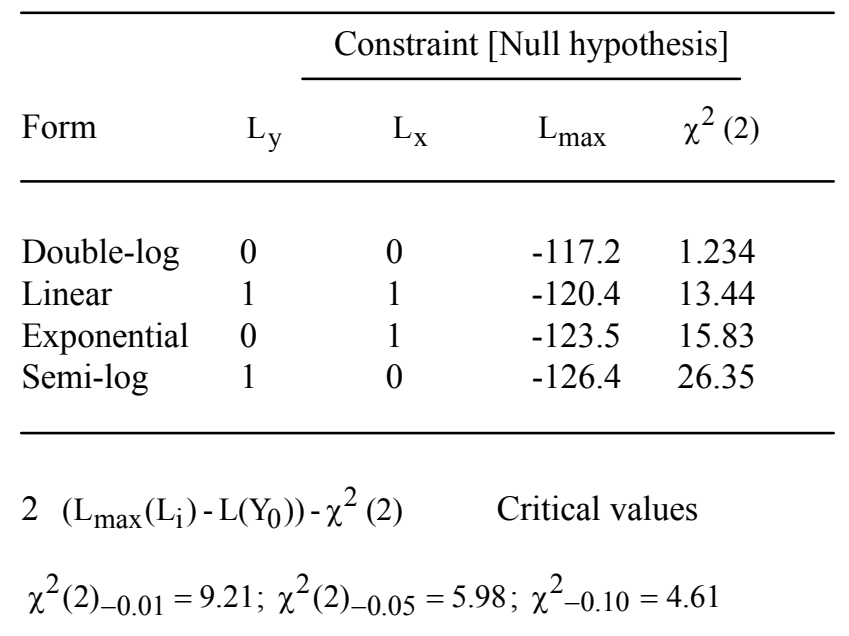

